\title{
ADMINISTRACIÓN PÚBLICA, CONSTITUCIÓN ESPAÑOLA Y PORTUGUESA Y DERECHOS FUNDAMENTALES EN LA PENÍNSULA IBÉRICA
}

\author{
PUBLIC ADMINISTRATION, SPANISH AND PORTUGUESE \\ CONSTITUTION AND FUNDAMENTAL RIGHTS IN THE IBERIAN \\ PENINSULA
}

\section{ADMINISTRAÇÃO PÚBLICA, CONSTITUIÇÃO ESPANHOLA E PORTUGUESA E DIREITOS FUNDAMENTAIS DA PENÍNSULA IBÉRICA}

RUBÉN MIRANDA GONÇALVES

Doctorado en Derecho Administrativo, Máster en Derecho de las Administraciones e Instituciones Públicas y Licenciado en Derecho con grado (sobresaliente) por la Universidade de Santiago de Compostela; Profesor colaborador de Derecho Administrativo en el Máster de Abogacía de la Universidad Europea de Madrid. Email: ruben.miranda@usc.es.

RUI MIGUEL ZEFERINO FERREIRA Profesor-Adjunto Invitado en el Instituto Superior de Entre Douro e Vouga (ISVOUGA). Profesor invitado en el Instituto Politécnico de Bragança; Doctorando en Derecho Público Especial (Tributario), en la Universidade de Santiago de Compostela; Máster en Derecho, de Ciencias Jurídico-Económicas, por la Facultad de de Derecho de la Universidade do Porto; Licenciado en Derecho, de Ciencias Jurídico-Económicas, por la Facultad de Derecho de la Universidade de Lisboa (Clássica); Juez-Árbitro del CAAD; Abogado. E-mail: zeferino_ferreira@sapo.pt 


\section{RESUMEN}

La característica esencial de un Estado de Derecho es el sometimiento de los diferentes poderes públicos al imperio de la ley. Por ello, tanto el poder ejecutivo, como el legislativo y el judicial están sometidos a la ley. Aún así no son los únicos, puesto que los ciudadanos y la propia Administración Pública no son ajenos a ello y también están obligados a cumplir la ley. El propio término Estado de Derecho lleva implícito el de derechos fundamentales, pues sin ellos, no podríamos hablar de Estado de Derecho.

PALABRAS CLAVE: Estado; Derechos Fundamentales; Derecho Administrativo; Derecho Constitucional; Gobierno; Derecho Público.

\section{ABSTRACT}

The essential characteristic of a State of Right is the submission of the different public powers to the empire of the law. Thus, so much the executive power, as the legislative and the judicial are submitted to the law. Still like this are not the only, since the citizen and the proper Public Administration aren't extraneous to this and also are forced to fulfill the law. The proper term Been of Right carries implicit the one of fundamental rights, so without them, couldn't speak of State of Right.

KEYWORDS: State; Fundamental Rights; Administrative Law; Constitutional Law; Govern; Public Law.

\section{RESUMO}

A característica essencial de um Estado de Direito é a submissão dos diferentes poderes públicos ao estado de direito. Portanto, ambos os poderes executivo, legislativo e judiciário estão sujeitos à lei. Mesmo assim, não são os únicos, pois os cidadãos e a própria Administração Pública não são alheios a isso e também são obrigados a cumprir a lei. O termo "Estado de Direito" em si implica o dos direitos fundamentais, porque sem eles, não poderíamos falar do Estado de Direito. 
PALAVRAS-CHAVE: Estado; Direitos fundamentais; Direito Administrativo; Direito Constitucional; Governo; Direito Público.

\section{INTRODUCCIÓN}

Ante las múltiples definiciones que podrían ofrecerse sobre qué es el Estado, la Real Academia Española señala que debe entenderse como la "forma de organización política, dotada de poder soberano e independiente, que integra la población de un territorio". De este concepto, se puede inferir, a grandes rasgos, que el Estado es la forma en la que la población se organiza social, política y económicamente. En el mismo sentido, y aportando una definición desde el punto de vista constitucional, Zafra Valverde $(1990$, p.74) señala que por Estado debe entenderse un:

[...] grupo territorial duradero, radicalmente comunitario, estrictamente delimitado, moderadamente soberano frente a otros, [...] en cuyo seno, sobre una población, con creciente homogeneidad y sentido de autopertenencia, una organización institucional eminentemente burocrática, coherente y jerarquizada, desarrolla una compleja gobernación guiada conjuntamente por las ideas de seguridad y prosperidad.

Por otro lado, la más notable doctrina administrativista portuguesa señala que el Estado se constituye por un pueblo, fijado en un territorio, del que es señor, y que dentro de las fronteras de ese territorio instituye, por autoridad propia, órganos que elaboran las leyes necesarias a la vida colectiva e impongan la respectiva ejecución. En este sentido puede consultarse (CAETANO, 2015, p.54).

En sentido más estricto, Diego Freitas do Amaral (2016, p.67) avanza en complemento del término pueblo con el de comunidad, por ser este "una de las diferencias específicas del concepto y no su género próximo". En lo que respecta a la definición, este autor llama la atención del contenido de la referencia al poder político, pues como afirma, la "función política es, por definición, tan importante como las 
funciones legislativa, administrativa y jurisdiccional, en la delimitación de la noción del poder político". En vistas a eso, este autor define al Estado como:

[...] la comunidad constituida por un pueblo que, a fin de realizar sus ideales de seguridad, justicia y bienestar, se adueña de un territorio e instituye en él, por autoridad propia, el poder de dirigir los destinos nacionales y de imponer las normas necesarias a la vida colectiva.

Aunque a veces se confunda, Estado no es lo mismo que gobierno, pues atendiendo nuevamente al significado de la RAE, el gobierno sería el "órgano superior del poder ejecutivo de un Estado o de una comunidad política, constituido por el presidente y los ministros o consejeros", y en otras palabras, el gobierno es "como una agencia especializada clocada al frente del Estado pero mucho menor que él" (MENAUT, 2010, p.215).

En suma, cuando hablamos del Estado, en primer lugar, tendremos que considerarlo como una comunidad humana de cariz político. En segundo lugar, resultan como elementos esenciales de este concepto la existencia de un pueblo, de un territorio y de un poder político. Por último, aunque no exista plena unanimidad, el Estado tendrá esencialmente tres fines: la seguridad, la justicia y el bienestar, como apuntan Maria Manuela Magalhães Silva e Dora Resende Alves (2000, p.133). Las mayores divergencias que afectan a este último fin, y que en las constituciones ibéricas encuentra un extenso desarrollo, es consecuencia del desarrollo de las teorías que sustentan la construcción del Estado Social, y ello no podrá dejar de estar sujeto a críticas. En la realidad, aunque tal objetivo sea meritorio, los mismos encierran consecuencias perversas en lo que respecta a la dimensión del Estado y a su grado de intervencionismo en la economía y en la sociedad.

En este sentido, asumimos que el bienestar económico y social debe ser un objetivo que debe ser alcanzado por la propia sociedad y no un fin del Estado, no presentándose como conforme al principio de la libertad individual o de la justicia conmutativa (o de medios) la imposición de un modelo económico, social o cultural a la sociedad. Por tanto, la despropositada intervención tiene como resultado una restricción inaceptable en los comportamientos y acciones de los ciudadanos. 
Aun así, para quienes defienden el fin del Estado, queda pendiente como asegurarán las condiciones de vida de los ciudadanos, posibilitando el acceso a bienes y servicios considerados fundamentales por la sociedad (MAGALHÃES; ALVES, 2000, p.134-135), como sucede con la salud, educación y seguridad social. Algunos elevan este fin a ser perseguido por el Estado, lo que sirvió para construir las teorías del Estado funcional. Con razón, Marcelo Rebelo de Sousa (2004, p.231) afirma que no se está ante un verdadero fin del Estado, por el hecho de que «el Estado se legitima por el grado de satisfacción del objetivo del bienestar económico y social'» (MAGALHÃES; ALVES, p.134, 2000).

Existen otras concepciones a propósito del Estado. La visión de la iglesia católica, en la que para Santo Tomás de Aquino el Estado seria el producto de la naturaleza social, racional y libre del hombre que exigiría una autoridad encargada de procurar el bien común. En esta visión, la sociedad y el Estado son resultado de la naturaleza, especialmente porque corresponden a una actuación que es consecuencia de los impulsos profundos y esenciales de los seres humanos. Por tanto, el Estado sería un producto de un acto voluntario, no de un contrato o pacto, pero de un consentimiento tácito común revelado en actos de cooperación.

Por otro lado, con la aparición del Estado de Derecho ${ }^{1}$, la Administración Pública, al igual que todos los ciudadanos, se somete al ordenamiento jurídico y debe asegurar una serie de derechos a sus ciudadanos cuando se relacionan con ella $\sin$ que exista ningún tipo de discriminación al respecto. Entre esos derechos se encuentran, como no puede ser de otra manera, los derechos fundamentales, de ahí que se hable de la existencia de una relación importante entre el Derecho Administrativo - rama del ordenamiento jurídico que regula las relaciones entre la Administración Pública y los ciudadanos - y los derechos fundamentales.

\footnotetext{
1 Puede profundizarse sobre la materia en: DÍAZ, p.7-8, 1997. DÍAZ; COLOMER, p.78, 2002. FERNÁNDEZ GARCÍA, p. 102, 2000.
} 


\section{ADMINISTRACIÓN PÚBLICA, GOBIERNO Y CONSTITUCIÓN ESPAÑOLA Y PORTUGUESA}

La Administración Pública y el Gobierno están integrados en el núcleo central de la idea de Estado moderno, fomentando así una idea de poder que, históricamente, se entendió que tendría que ser limitado para que pudiésemos considerar estar ante un Estado moderno. Tal y como defendió Maquiavelo, el individuo y sus derechos fundamentales son los elementos fundamentales de las sociedades modernas, que se apoyan más allá de la idea de soberanía nacional, en los principios del Estado de Derecho, en la igualdad y en desarrollo del bienestar social y económico.

En el Título IV de la Constitución Española - artículos 97 a 107- se hace alusión al Gobierno y la Administración. En los títulos IV y IX de la Constituição da República Portuguesa se hace referencia al Gobierno y a la Administración Pública, siendo particularmente relevante la definición de Gobierno, las responsabilidades del Gobierno y sus competencias, respectivamente en los artículos $182 . .^{\circ}, 190$. e e 197.a a 201.ㅇ de la referida Constitución portuguesa; por otro lado, en los artículos 226. 272. . se constitucionaliza la Administración Pública, en especial sus principios de actuación y estructura organizativa.

En este sentido, se desprende que en las Constituciones ibéricas es el gobierno quien dirige la política interior y exterior, la Administración civil y militar y también la defensa del Estado. Además, el mismo artículo $97 \mathrm{CE}$ señala que el gobierno es el titular del poder ejecutivo y ejerce también la potestad reglamentaria de acuerdo con la propia Constitución y las leyes. Lo mismo resulta del artículo 182. de la CRP, del cual se infiere que el Gobierno es el órgano de conducción de la política general del país y el órgano superior de la administración pública, lo que concretiza en otras disposiciones constitucionales, especialmente por vía de la tripartición de las competencias entre políticas, legislativas y administrativas como se recoge en los artículos 197.․, 198. y 199. de la CRP. De ese conjunto de competencias deben destacarse las competencias administrativas constantes del ya referido artículo 199.ำ de la CRP, especialmente, Dirigir los servicios y la actividad de la administración directa del Estado, civil y militar, superentender en la administración indirecta y ejercer 
la tutela sobre esta y sobre la administración autónoma²; Defender la legalidad democrática ${ }^{3}$; y Practicar todos los actos y tomar todas las providencias necesarias a la promoción del desarrollo económico-social y a la satisfacción de las necesidades colectivas ${ }^{4}$.

Por lo que respecta a la Administración Pública, normalmente aparece asociada a la idea de función administrativa, pero la misma comporta varios sentidos, pues, para unos, tiene un sentido material, formal, orgánico y, para otros, un sentido funcional. En sentido material, y recurriendo a las palabras de Marcelo Rebelo De Sousa y André Salgado Matos (2009), corresponde a la actividad concreta en que se traduce el ejercicio de la función administrativa del Estado. Por eso, Freitas do Amaral sustenta que la noción de Administración Pública estaría relacionada con la actuación de los órganos de la administración en sentido orgánico. Esta administración corresponde a la actividad típica de los servicios y agentes administrativos desarrollada para el interés general de la colectividad, para satisfacer mejor las necesidades colectivas, de forma regular y continua.

Con todo, al atender al modo en como la actividad administrativa incide en la esfera social, podemos encontrar una administración agresiva, prestacional e intraestatal, que será aquella que resulta de actuaciones de naturaleza de intromisión en la esfera jurídica de los individuos y que restringe sus derechos e intereses. Su naturaleza prestacional resulta de la concepción de Estado Social y de su atribución de ventajas. Por último, la naturaleza intraestatal resulta de la idea de programación de la persecución futura del interés público.

A su vez, en sentido orgánico, corresponderá al conjunto de personas colectivas que ejercen la función administrativa a título principal. En palabras de Freitas do Amaral (2016), corresponde a un "sinónimo de organización administrativa", en que la administración comprende a las personas colectivas públicas y de los servicios administrativos, y los funcionarios y agentes administrativos.

\footnotetext{
2 Cfr. Artigo 199.ำ letra d), da CRP

${ }^{3}$ Cfr. Artigo 199. ${ }^{\circ}$, letra f), da CRP

${ }^{4}$ Cfr. Artigo 199. ${ }^{\circ}$, letra g), da CRP
} 
A pesar de esta clásica distinción $n^{5}$, la noción de Administración Pública ha sido descaracterizada, por vía del recurso a la admisión de personas colectivas de creación y control público sobre la forma privada y de personas puramente privadas, disciplinadas por el derecho privado, aunque sujetas a un régimen de control público.

En síntesis, coincidimos con FREITAS DO AMARAL cuando señala que, cuando se habla de Administración pública, se tiene presente todo un conjunto de necesidades colectivas cuya satisfacción es asumida como tarea fundamental por la colectividad, a través de servicios organizados y mantenidos por esta.

Dicho esto, la Constituição da República Portuguesa, al contrario de la Constitución Española, la autonomiza en un título propio, como resultando de su artigo 266. por lo que esta debe proseguir en primera línea el interés público, resultante de los derechos e intereses legalmente protegidos de los ciudadanos, por lo que los órganos y agentes administrativos están subordinados a la Constitución y a la ley y deben actuar, en el ejercicio de sus funciones, con respecto por los principios de igualdad, de proporcionalidad, de justicia, de imparcialidad y de buena fe. Además, esto debe hacerse en base en una estructuración que debería garantizar - e no garante - la simplicidad administrativa, para que, en palabras del texto constitucional, evitar la burocratización, aproximar los servicios de las poblaciones y asegurar la participación de los interesados en su gestión efectiva.

Luego, La Administración Pública, tal y como se infiere ahora del artículo 103.1 de la Constitución Española, "sirve con objetividad los intereses generales y actúa de acuerdo con los principios de eficacia, jerarquía, descentralización, desconcentración y coordinación, con sometimiento pleno a la ley y al Derecho" ${ }^{6}$. Esto significa que la Administración Pública tiene que ser objetiva, neutra e imparcial con todos los ciudadanos por igual para garantizar sus derechos y será el Derecho Administrativo quien garantice ese interés general.

\footnotetext{
${ }^{5}$ Encontramos la posición de Figueiredo Dias y Fernanda Paula Oliveira, en que la administración pública en sentido funcional corresponde a un conjunto de actividades desarrolladas por los órganos designados en la administración en sentido orgánico, de modo a desarrollar e a realizar la tarea global de la administración.

${ }^{6}$ A este propósito la Constituição da Republica Portuguesa señala en su artículo 267.ํ, n.ำ 2, que "[...] la ley establecerá formas adecuadas de descentralización y desconcentración administrativas, sin prejuicio de la necesaria eficacia y unidad de acción de la Administración y de los poderes de dirección, superintendencia y tutela de los órganos competentes".
} 
Además, eso mismo se contempla en el artículo 9.ํ del Código de Procedimiento Administrativo portugués, que regulando el principio de la imparcialidad, consagra la obligación legal de la Administración Pública de tratar de forma imparcial todos aquellos que se relacionen con ella, "considerando con objetividad todos y apenas los intereses relevantes en el contexto decisorio y dotando las soluciones organizadoras y procedimentales indispensables a la preservación de la exención administrativa e a la confianza en esa exención".

Rodriguez Arana (2011, p.93) sostiene que la caracterización que hace el artículo 103.1 de la Constitución Española sobre la función Administrativa en el Estado social y democrático de Derecho, no podría haber sido mejor. "Primero, porque la expresión servicio indica certeramente el sentido y alcance del papel de la Administración en relación con la ciudadanía" y, "segundo, porque la instauración del sistema constitucional en las democracias supone un paso relevante en orden al necesario proceso de objetivización del poder que supone la victoria del Estado liberal sobre el Antiguo Régimen" (2011, p.93).

Cuando la Administración Pública no cumple con todo lo anterior, incurre en responsabilidad, así se infiere del artículo 106.2 de la Constitución Española "Los particulares, en los términos establecidos por la ley, tendrán derecho a ser indemnizados por toda lesión que sufran en cualquiera de sus bienes y derechos, salvo en los casos de fuerza mayor, siempre que la lesión sea consecuencia del funcionamiento de los servicios públicos".

Lo mismo resulta del ordenamiento jurídico portugués, pues la constitución señala que los funcionarios y los agentes del Estado y de las demás entidades públicas son responsables civil, criminal y disciplinariamente por las acciones $u$ omisiones practicadas en el ejercicio de sus funciones de las cuales derive la violación de los derechos o intereses legalmente protegidos de los ciudadanos.

Así, por un lado, el identificado Código do Procedimento Administrativo, consagra en su artículo $16 .$. el principio de la responsabilidad ${ }^{7}$ y, por otro, el legislador previó en la Ley n.- 67/2007, de 31 de diciembre, el régimen propio de la responsabilidad extracontractual del Estado, por vía de la cual prolongó la

\footnotetext{
7 Según esta disposición legal "La Administración Pública responde, en los términos de la ley, por los daños causados en el ejercicio de su actividad".
} 
responsabilidad civil a las funciones administrativa, legislativa y judicial ${ }^{8}$. Esa responsabilidad también se dará, como es evidente, en caso de que la Administración Pública viole cualquiera de los derechos fundamentales reconocidos a los ciudadanos.

\section{DERECHOS FUNDAMENTALES Y DERECHOS HUMANOS}

Está aceptado por la doctrina que el término derechos fundamentales, como tal, aparece tras la Declaración de los Derechos del Hombre y del Ciudadano de 1789, la cual se convierte en el primer texto en el que aparecen citados los derechos fundamentales. "Los derechos fundamentales son un concepto histórico del mundo moderno que surge progresivamente a partir del tránsito a la modernidad" (PECESBARBA MARTÍNEZ, p.11, 1987).

No obstante, ello no quiere decir que antes de 1789 no existiesen elementos que son fundamentales para determinar este concepto, pues ya en textos anteriores - no de derechos fundamentales - aparecía, como señala PECES-BARBA, referencias a la dignidad:

[...] la idea central, que podemos encontrar en todo momento histórico, será la de la dignidad humana. En cada tiempo se realiza de acuerdo con las condiciones económicas, sociales, culturales y políticas y solo en el mundo moderno a través de los derechos fundamentales [...] la persona reclamará su libertad religiosa, intelectual, política y económica (PECES-BARBA MARTÍNEZ, p.11, 1987).

Este proceso de evolución, para PECES-BARBA se debe a un triple proceso: "la positivización, la generalización y la internacionalización" (PECES-BARBA MARTÍNEZ, p.13, 1987). Primero, incluyendo los derechos fundamentales en las diferentes Constituciones; segundo, introduciendo "componentes igualitarios (...), económicos, sociales y culturales que pretenden mejorar la condición del trabajador, la sanidad, la educación o la cultura" (PECES-BARBA MARTÍNEZ, p.14, 1987); y tercero, "superar el ámbito del Estado nacional y su soberanía para su reconocimiento y protección" (PECES-BARBA MARTíNEZ, p.14, 1987).

8 Vide Gomes, p.36-49, 2004; LACERDA, p. 239-260 1986. 
Es importante señalar que el término derechos humanos y derechos fundamentales, aunque existen autores como Durán Martínez (p. 129, 2007) que los usan como sinónimos, en nuestra opinión no lo son. Consideramos que no pueden usarse como sinónimos porque todos los derechos fundamentales son derechos humanos, pero no todos los derechos humanos son derechos fundamentales.

Los derechos fundamentales y los derechos humanos no siempre corresponden a situaciones jurídicas de fácil distinción, especialmente, en su ámbito conceptual. Tendrán que considerarse como tales, las posiciones jurídicas reconocidas por el derecho nacional, europeo e internacional, en aras a la defensa de los valores, e intereses más relevantes, tanto de personas singulares como de personas colectivas en un determinado territorio, independientemente de la nacionalidad que posean.

Según Jónatas Machado (1996, p.161-162) existen diferentes tesis, por lo que señala que:

\begin{abstract}
La primera tesis [de los derechos fundamentales], de inspiración preponderantemente lockeana y kantiana, corresponde al pensamiento de autores como Rawls, Dworkin, Richards, etc., que partiendo de tesis neocontractualistas o de un discurso filosófico político-moral, procuran identificar un conjunto de derechos fundamentales deducidos a partir de principios de justicia (fairness) o de prerrogativas morales de la personalidad, afirmando su innegociable prioridad en la ordenación de la comunidad política.
\end{abstract}

En la contemporaneidad, los derechos fundamentales son reconocidos como hechos firmes, pero importa señalar que estos derechos simplemente fueron consagrados en la época moderna. Esto es, a partir de las revoluciones liberales francesa y americana, donde tales derechos fueron inseridos en las respectivas cartas y constituciones.

A pesar de su tardía consagración y lento desarrollo, hay quien considera su preexistencia con fundamento en el hecho de que los mismos nacerían con el individuo y no por la concesión del Estado. Por tanto, de esta línea de pensamiento, resulta que los derechos fundamentales serían preexistentes a todas las instituciones políticas y sociales, por lo que no podrían ser retirados o restringidos por éstas.

Para Gomes Canotilho (1993) los derechos fundamentales son sinónimos de los derechos del hombre, y sólo podremos distinguirlos diciendo que, los derechos del 
hombre son derechos naturales, válidos a todos los pueblos y a todos los tiempos, en cuanto que los derechos fundamentales son derechos del hombre garantizados jurídicamente. Por eso, en esta línea, los derechos fundamentales se constituyen bajo el punto de vista objetivo de normas de competencia para los poderes públicos, prohibiendo la injerencia del Estado en la esfera jurídico-individual de cada uno de los individuos.

Por otro lado, Gomes Canotilho $(2003$, p.378) ve el proceso de constitucionalización de los derechos fundamentales como "[...] incorporación de derechos subjetivos del hombre en normas formalmente básicas, sustrayendo su reconocimiento y garantía a la disponibilidad del legislador originario". Jorge Miranda (1999, p.11) considera que se tratan de "derechos o posiciones jurídicas subjetivas de las personas como tales, individual o institucionalmente consideradas, asentadas en la Constitución".

Según nos parece, la diferencia entre derechos fundamentales y derechos humanos debe ser encontrada en la fuente de cada uno de ellos, pues, mientras los primeros tendrán consagración en los textos constitucionales, los segundos harán parte del derecho internacional, sin perjuicio de que también consten en los textos constitucionales, pero que ocurrirá más por obligaciones internacionales de los diferentes Estados. Así, conforme defiende Gomes Canotilho y Vital Moreira (2007, p.240), los derechos humanos:

[...] se distinguen de los derechos fundamentales porque estos son los derechos constitucionalmente positivizados y jurídicamente garantizados en el ordenamiento jurídico, en cuanto los derechos humanos son los derechos de todas las personas o colectivos de personas independientemente de su positivización jurídica en los ordenamientos político-estatales.

Basta con observar las diferentes Constituciones para observar que muchos de los derechos humanos no están contemplados como fundamentales. Por ejemplo, el artículo 23 de la Declaración Universal de Derechos Humanos, recoge el derecho al trabajo y derecho a igual salario por trabajo igual. En ese sentido, el artículo 24 del mismo texto, regula el derecho al descanso, tiempo libre y vacaciones. Otro ejemplo sería el famoso derecho de autodeterminación, recogido en los Pactos Internacionales de Derechos Humanos, reconocido como un derecho humano, pero no un derecho 
fundamental (GONÇALVES; NEIRA, 2015, p.395). Todos ellos son derechos humanos, pero no derechos fundamentales.

Como expresó José De Melo Alexandrino (2007, p.30), los derechos fundamentales corresponderán a las situaciones jurídicas fundamentales de las personas a las que se dirige una determinada constitución, y los derechos humanos serán los de naturaleza humana y que el derecho internacional reconoce, por lo que en los primeros hay una necesidad de positivizarlos, mientras que en los segundos no. A pesar de ello, la complejidad es evidente, desde luego, porque reconocemos que sus características principales serán comunes, su carácter fundamental, universalidad, inalienabilidad, indivisibilidad, interdependencia e interrelación.

En el caso de la Constitución de la República Portuguesa, podemos subdividir los derechos fundamentales en varias categorías ${ }^{9}$. Los derechos fundamentales individuales o institucionales; derechos fundamentales universales; derechos, libertades y garantías y derechos económicos, sociales y culturales; y derechos formalmente constitucionales y derechos sólo materialmente fundamentales.

Siguiendo el pensamiento de GOMES CANOTILHO, los derechos fundamentales tienen como propósito garantizar la no discriminación, la libertad, el respeto de prestación social y de protección ante conductas de terceros. No obstante, subyacente a la idea de no discriminación está el ideal de igualitarismo del Estado Social, que implica tratar de forma igual todo lo que sea igual y de modo diverso lo que sea diferente. Ello se aplica tanto a los derechos fundamentales como a los derechos humanos, de naturaleza civil, política, derechos económicos, sociales y culturales.

Por lo que respecta a su objetivo de garantizar la libertad (o defensa), se tiene en mente la salvaguarda de la dignidad de la persona humana ante los poderes que el Estado puede ejercer sobre los ciudadanos, que tiene consagración en el artículo

\footnotetext{
${ }^{9}$ Se sigue la categorización más próxima de Jorge Miranda, una vez que aquella que se efectúa por Gomes Canotilho se centra en la actuación estatal, a través de la distinción entre derechos de defensa y derechos a prestaciones, bien como entre derechos fundamentales formalmente constitucionales y derechos fundamentales sin base constitucional y derechos formal y materialmente constitucionales. Al revés, Jorge Miranda y José De Melo Alexandrino identifican como categorías los derechos fundamentales individuales e institucionales, comunes y particulares, libertades y garantías y derechos, libertades y garantías y derechos sociales, siendo que este último autor categoriza las garantías de acuerdo con su fuente ya su fuerza jurídica.
} 
1.. de la CRP, a cuyo tenor "Portugal es una República soberana, basada en la dignidad de la persona humana y (...) empeñada en la construcción de una sociedad libre, justa y solidaria". Ello se encuentra especialmente previsto en los derechos, libertades y garantías personales, asumiendo tanto una vertiente positiva como negativa.

El fin de garantizar la prestación social se insiere igualmente en la lógica del funcionamiento del Estado Social, en donde están los derechos a la salud, educación y seguridad social, obtenidos por la intervención del Estado en la sociedad. Así, en particular, es posible encontrar este fin en los derechos económicos, sociales y culturales.

El fin último en el que se refiere a la protección ante terceros, posibilita constatar la existencia de una naturaleza que trasciende a la mera relación entre los individuos y el Estado, abarcando igualmente la relación entre individuos. Este objetivo tiene el efecto de obligar al Estado a actuar en el sentido de crear normas reguladoras capaces de proteger los derechos fundamentales de los individuos en relación a los demás miembros de la comunidad.

En el contexto de los derechos fundamentales y de los derechos humanos también se pronuncia el profesor PÉREZ LUÑO cuando señala que el término derechos humanos es más amplio e impreciso que la noción de derechos fundamentales.

\footnotetext{
Los derechos humanos suelen venir entendidos como un conjunto de facultades e instituciones que, en cada momento histórico, concretan las exigencias de la dignidad, la libertad y la igualdad humana, las cuales deben ser reconocidas positivamente por los ordenamientos jurídicos a nivel nacional e internacional. En tanto que con la noción derechos fundamentales, se tiende a aludir a aquellos derechos humanos garantizados por el ordenamiento jurídico positivo, en la mayor parte de los casos en la norma constitucional (PÉREZ LUÑO, 2013).
}

No obstante, no todos los derechos fundamentales tendrán la misma importancia, lo que derivará de las diferentes generaciones de derechos y su importancia relativa de unos en relación a otros. Los derechos fundamentales fueron institucionalizados con base en cuatro generaciones, en las que la primera generación señala respeto a derechos como la libertad, los cuales tienen como titulares a los 
individuos y corresponden a derechos civiles y políticos de aplicabilidad inmediata y directa. Deben ser entendidos como facultades o atributos del individuo, por lo que siendo subjetivos implican que sean vistos como derechos individuales de resistencia o de oposición ante el Estado.

La segunda generación de derechos fundamentales nació en el siglo XX y comprendía los derechos civiles, sociales, económicos y también los derechos colectivos, los cuales son el resultado del desarrollo de la idea de Estado social. De esa introducción surgió la creación de una multitud de nuevos derechos. Estos derechos, distintos de los anteriores, son de aplicación mediata y, por tanto, dependen de la actuación del Estado-legislador. Además, la introducción de estos derechos condujo a una modificación de la percepción de los principios de igualdad y libertad, pues se tuvieron en cuenta una dimensión más acentuada para impedir el arbitrio del Estado contra estos "nuevos" derechos.

La tercera generación de derechos tendrá una correspondencia con aquellos que se presentan con un elevado grado de humanismo y universalidad, que se consolidan definitivamente a final del siglo XX. Estos derechos se destinan a garantizar la protección de los intereses de los individuos y de grupos de individuos y valores supremos como la paz y el ambiente. Por último, nos encontraríamos con los derechos de cuarta generación, referentes a la institucionalización del Estado Social, como el derecho a la democracia, información y pluralismo.

Con la aparición de los derechos fundamentales, el derecho administrativo sufre una gran modificación porque su estructura, centrada en el poder del Estado, es redimensionada de modo a centrarse en el individuo y en la colectividad. De este modo se produjo el reconocimiento del papel del individuo y de los derechos públicos subjetivos de cara a la anterior supremacía del Estado.

Como resultado de esta modificación estructural, el Estado tiene que cumplir con determinados deberes negativos y positivos. Esto acarreó la necesidad de interpretar las constituciones, en las que el Estado pasa a tener deberes positivizados y obligaciones que correspondían a derechos y pretensiones de los particulares, especialmente a través de la introducción y desarrollo del principio de la participación de los particulares en el procedimiento administrativo y en las decisiones políticolegislativas. 
Por tanto, los derechos fundamentales promoverán la modificación en las relaciones entre la Administración Pública y los administrados, reorientando la persecución del interés público. Ello nos lleva a que en el procedimiento administrativo portugués se haga alusión en paralelo con la persecución del interés público, al respeto por los derechos e intereses legalmente protegidos de los ciudadanos ${ }^{10}$. Además de lo anterior, el Estado fruto de esos derechos fundamentales o, en lenguaje del CPA portugués, los derechos e intereses legalmente protegidos, pasó a estar sujeto al cumplimiento del principio de legalidad que limita la amplitud de sus decisiones.

La legalidad se ha vuelto un principio fundamental del derecho público $\mathrm{y}$, en especial, del derecho administrativo, como parámetro que regula la actuación y los comportamientos de la administración pública.

La evolución del Derecho Administrativo, por su influencia, es notoria con la introducción de nuevas garantías que pueden ser ejemplificadas por derecho de petición, donde el individuo puede contestar los actos administrativos derivados de la acción del Estado o, a falta de ella, por comportamientos de omisión, bien como por la obligación de respeto y garantía por el derecho a la libertad en sentido más amplio, es decir, con la posibilidad de exigirse la abstención, revocación, reconsideración o anulación del acto estatal, a mayores de la defensa o protección contra actos de terceros a los que puedan dañar.

Por último, debemos destacar que los servicios de la Administración Pública pasaron a ser instrumentos para la realización de los derechos fundamentales, es decir, deben promover la garantía de un núcleo mínimo necesario a la preservación de la dignidad de la persona humana. El cambio de paradigma obligó a las entidades públicas a ponderar los intereses privados en relación a los intereses públicos para garantizar la tutela de los derechos fundamentales de los individuos en relación al propio Estado, especialmente, por vía de la exigencia de fundamentación de las decisiones que impliquen una restricción de derechos, como el deber de recurrir a la utilización del principio de proporcionalidad.

${ }^{10}$ Cfr. artículo 4. del Código de Procedimento Administrativo portugués 


\section{RELACIÓN ENTRE DERECHO ADMINISTRATIVO, ADMINISTRACIÓN PÚBLICA Y DERECHOS FUNDAMENTALES}

Anteriormente se hacía referencia a que todo Estado de Derecho supone el pleno sometimiento del propio ente al imperio de la ley. Un Estado que no garantice el principio de igualdad, no es un Estado democrático y por ende, no protege la libertad de sus ciudadanos y genera discriminación.

Los principios de igualdad y de legalidad son fundamentales para entender la relación entre el Estado y sus ciudadanos y el sometimiento a la ley se traduce en el respeto de los ciudadanos y poderes públicos a todo el ordenamiento jurídico de un Estado, empezando, como es evidente, por el respeto a la Constitución.

Sería inconcebible hablar de Estado de Derecho sin derechos fundamentales, pues son de vital importancia y para ello, el Estado tiene que garantizar la protección de los derechos fundamentales de sus ciudadanos frente a los ataques que puedan recibir de terceros, incluida la Administración Pública, que debe servir al ciudadano (DEL MASSO; MIRANDA GONÇALVES; ZEFERINO FERREIRA, 2015, p.306). En este sentido, es cuando entra en juego el Derecho Administrativo. En palabras de Justen Filho (2006), el Derecho Administrativo viene a ser:

[...] el conjunto de normas jurídicas de Derecho Público que disciplinan las actividades administrativas necesarias para la realización de los derechos fundamentales y la organización y el funcionamiento de las estructuras estatales y no estatales encargadas de su funcionamiento.

Es aquí cuando el Estado asume un papel relevante para garantizar el interés general al que hacíamos referencia en páginas anteriores y para garantizar los derechos y libertades ciudadanas (RODRíGUEZ-ARANA MUÑOZ, 2011, p.77), por ello, sin libertad e igualdad, difícilmente se podría hablar de un Estado democrático y de Derecho.

Efectivamente, el Estado al no actuar de esta forma incurrirá en responsabilidad, pues, si de su actuación o falta de actuación, se violase un derecho fundamental, el Estado podría ser responsabilizado tanto por acción como por 
omisión, la cual podrá ser complementada con la responsabilidad internacional del Estado.

Cuando se produzca responsabilidad del Estado por la violación de derechos fundamentales, esta responsabilidad es extiende a las violaciones de derechos, libertades y garantías o de derechos económicos, sociales y culturales ${ }^{11}$, una vez que lo que importa determinar, en sede de responsabilidad civil, es la existencia de daños que deriven de actividades prácticas por titulares de órganos, funcionarios o agentes en el ejercicio de sus funciones.

Como apunta la doctrina portuguesa, la responsabilidad del Estado está relacionada con el principio del Estado de Derecho y también con el principio de constitucionalidad de la acción del Estado y con el principio de igualdad (CANOTILHO; MOREIRA, 2007). Por tanto, no sólo la libertad y la igualdad deben ser respetadas por las Administraciones Públicas, ya que no son los únicos derechos fundamentales que existen, pues también se encuadran dentro de los derechos fundamentales el derecho a la vida y a la integridad física y moral; el derecho a la libertad ideológica, religiosa y de culto de los ciudadanos; el derecho a la seguridad; el derecho al honor, intimidad personal, familiar y propia imagen; el derecho a la libertad de expresión y el derecho a la tutela judicial efectiva de los jueces y tribunales sin que pueda producirse indefensión, entre otros.

Como se ha dicho, la Administración Pública no es ajena a ese respeto de los derechos fundamentales de sus administrados y por tanto, tiene que respetarlos. En caso contrario, y ante cualquier lesión ${ }^{12}$ que sufran en sus bienes o derechos, ya sea por el funcionamiento normal o anormal de los servicios públicos, serán indemnizados. Esta indemnización tendría lugar salvo en los casos de fuerza mayor o de daños que el particular tenga el deber jurídico de soportar de acuerdo con la Ley.

En este contexto, el acceso a la justicia administrativa se reviste de mayor importancia en el ámbito de la tutela de los derechos fundamentales, a través del

\footnotetext{
${ }^{11}$ En la jurisprudencia brasileña y portuguesa, pueden encontrarse ejemplos de responsabilidad del Estado relacionada con el derecho a la salud. Por ejemplo, la sentencia del Tribunal Regional Federal de la 1르 Región, Sentencia de 31 de mayo de 2004 (proceso número AC 5578 GO 2001.35.00.0055786), bien como la sentencia del Supremo Tribunal Administrativo de Portugal, de 12 de abril de 2012 (Proceso número 0798/11).

${ }^{12}$ En todo caso, el daño alegado habrá de ser efectivo, evaluable económicamente e individualizado con relación a una persona o grupo de personas.
} 
acceso a los tribunales, que se muestra fundamental para garantizar la defensa de la violación de derechos fundamentales de los particulares contra el Estado. En Portugal, el derecho de acceso a la justicia administrativa, como derecho de los administrados, se hizo autónomo, pues en virtud del artículo 268.․ apartado 4 y 5 , de la CRP, se "garantiza a los administrados la tutela jurisdiccional efectiva de sus derechos o intereses legalmente protegidos, incluyendo, especialmente, el reconocimiento de esos derechos o intereses, la impugnación de cualesquiera actos administrativos que los dañen, independientemente de su forma, la determinación de la práctica de actos administrativos legalmente debidos y la adopción de medidas cautelares adecuadas". El apartado siguiente señala que "los ciudadanos tienen, igualmente, el derecho a impugnar las normas administrativas con eficacia externa lesivas de sus derechos o intereses legalmente protegidos":

Existe una relación próxima e íntima entre la justicia administrativa y el principio del Estado de Derecho para la defensa de los derechos fundamentales, lo que deriva de la vinculación de la Administración Pública a las leyes ordinarias y a la Constitución.

En efecto, Jónatas Machado (2013, p.212), apunta que:

\begin{abstract}
[el] principio del Estado de Derecho, al determinar la subordinación de toda actividad del Estado a la Constitución y a la ley, es incompatible con la sustracción de la función administrativa al control jurisdiccional. En todas sus acciones y omisiones, jurídicas o materiales, la misma debe observar los principios fundamentales de la orden constitucional y las normas emanadas por el legislador democrático. El principio del Estado de Derecho, conjuntamente con el principio de la tutela judicial efectiva de los particulares, postula la existencia de un control independiente, imparcial y eficaz de esa observancia, basado en parámetros jurídico normativos y no en criterios de naturaleza política.
\end{abstract}

Dicho esto, todo particular que sea lesionado en un derecho fundamental, podrá acceder a la justicia administrativa y, en particular, a los tribunales para obtener la tutela del derecho. Además, está expresamente previsto en el artículo $8 .^{\circ}$ del Código de Procedimento Administrativo portugués el principio de justicia, que impone a la Administración Pública el tratamiento de forma conforme a los dictámenes de justicia, lo que necesariamente implica el rechazo de comportamientos contrarios a los derechos fundamentales constitucionalizados. 
En España, tanto la Constitución -tal y como hemos visto anteriormente en su artículo 106.2- como la nueva Ley 40/2015, de 1 de octubre, de Régimen Jurídico del Sector Público, prevén la responsabilidad patrimonial de las Administraciones Públicas. En cuanto al ordenamiento jurídico portugués, el régimen de la responsabilidad extracontractual del Estado fue consagrado en la Ley n. $.07 / 2007$, de 31 de diciembre, que da cumplimento al principio de la responsabilidad previsto en el Código de Procedimiento Administrativo (artículo 16.ํ), según el cual "La Administración Pública responde, en los términos de la ley, por los daños causados en el ejercicio de su actividad".

Para lo que nos interesa en este ámbito, estará en causa la responsabilidad del Estado-administración, cuando entendemos que para existir responsabilidad de la Administración Pública no podrá haber un acto ilegal, pudiendo estar ante un mero acto contrario al principio de justicia, pero que por su naturaleza podrá ser sólo por si suficiente para entenderse violado un derecho fundamental y así implicar responsabilidad del Estado. Esto ocurre en el caso portugués según el artículo 266., n. .2 , de la CRP, que autonomiza el principio de justicia en relación al principio de legalidad, el que ya fue aceptado por la jurisprudencia administrativa al anular un acto injusto aún sin probar que era ilegal.

Esta responsabilidad es solidaria entre la Administración y los funcionarios o agentes. En este último caso, la administración tendrá el derecho de regreso sobre los respectivos funcionarios, sin perjuicio del régimen de la culpa del servicio. Asimismo, como ocurrió en España, hay que exigir tanto de la ley como de la jurisprudencia, que se restrinjan al mínimo los casos en los que puede proceder a la invocación de la culpa del servicio, para que no haya tentación de diluir en el servicio responsabilidades individuales de agentes.

\section{OTROS DERECHOS DE LOS CIUDADANOS FRENTE A LA ADMINISTRACIÓN PÚBLICA ESPAÑOLA}

Antes de terminar con este capítulo, resulta conveniente hacer alusión a otros derechos que, aunque no tienen el rango de fundamentales, también pueden ser 
reclamados por los ciudadanos frente a las Administraciones Públicas españolas. Para ello debemos acudir al artículo 13 de la Ley 39/2015, de 1 de octubre, del procedimiento Administrativo Común de las Administraciones Públicas, el cual establece los Derechos de las personas en sus relaciones con las Administraciones Públicas. En este sentido, cualquier ciudadano con capacidad de obrar ante las Administraciones Públicas españolas, es titular de los siguientes derechos:

"a) A comunicarse con las Administraciones Públicas a través de un Punto de Acceso General electrónico de la Administración.

b) A ser asistidos en el uso de medios electrónicos en sus relaciones con las Administraciones Públicas.

c) A utilizar las lenguas oficiales en el territorio de su Comunidad Autónoma, de acuerdo con lo previsto en esta Ley y en el resto del ordenamiento jurídico.

d) Al acceso a la información pública, archivos y registros, de acuerdo con lo previsto en la Ley 19/2013, de 9 de diciembre, de transparencia, acceso a la información pública y buen gobierno y el resto del Ordenamiento Jurídico.

e) A ser tratados con respeto y deferencia por las autoridades y empleados públicos, que habrán de facilitarles el ejercicio de sus derechos y el cumplimiento de sus obligaciones.

f) A exigir las responsabilidades de las Administraciones Públicas y autoridades, cuando así corresponda legalmente.

g) A la obtención y utilización de los medios de identificación y firma electrónica contemplados en esta Ley.

h) A la protección de datos de carácter personal, y en particular a la seguridad y confidencialidad de los datos que figuren en los ficheros, sistemas y aplicaciones de las Administraciones Públicas.

i) Cualesquiera otros que les reconozcan la Constitución y las leyes".

Para concluir, hay que hacer referencia al derecho y obligación que tienen los ciudadanos para relacionarse con la Administración pública vía electrónica si ésta lo requiere. Esta es una novedad que se da en esta Ley de 2015, pues no estaba prevista en la antigua Ley 30/1992, de 26 de noviembre, de Régimen Jurídico de las Administraciones Públicas y del Procedimiento Administrativo Común. 


\section{CONCLUSIÓN}

Todos ciudadanos de un Estado, a través de la Constitución, tienen reconocidos una serie de derechos que son fundamentales y, en base al principio de igualdad, son iguales ante la ley. Ello se traduce también en el ámbito de la Administración Pública, pues todos los ciudadanos tienen que ser tratados igualmente, sin ningún tipo de discriminación que pueda causarle agravio o perjuicio frente a terceros.

La Administración Pública no es ajena a ese respeto de los derechos fundamentales de sus administrados y por tanto, tiene que respetarlos. En caso contrario, y ante cualquier lesión que sufran en sus bienes o derechos, ya sea por el funcionamiento normal o anormal de los servicios públicos, serán indemnizados. Esta indemnización tendría lugar salvo en los casos de fuerza mayor o de daños que el particular tenga el deber jurídico de soportar de acuerdo con la Ley.

\section{REFERÊNCIAS}

ALEXANDRINO, José de Melo. Direitos Fundamentais: Introdução Geral. Principia, 2007.

ALEXY, Robert. Teoria dos direitos Fundamentais. Edição Malheiros, São Paulo, 2008

ANDRADE, José Carlos Vieira de. Direitos Fundamentais na Constituição de 1976, Coimbra, Almedina, 2001

BRASIL. Acórdão do Tribunal Regional Federal da 1. ${ }^{a}$ Região, de 31 de Maio de 2004 (Processo n.- AC 5578 GO 2001.35.00.005578-6), Brasil, consultado em https://www.jusbrasil.com.br/diarios/TRF-1/. Último acesso: 27 de julho de 2017.

(Processo no 0798/11), Portugal, consultado em https://blook.pt/caselaw/PT/STA/371788/?q=processo:\%200798/11. Último acesso: 27 de julho de 2017.

CAETANO, Marcello. Manual de Ciência Política e Direito Constitucional. Tomo I, Almedina, Coimbra 2015 
CANOTILHO, Gomes. Direito Constitucional E Teoria Da Constituição. 7.. Ed., Coimbra: Almedina, 2003.

. Direito Constitucional, Almedina. Coimbra, 1993.

; MOREIRA, Vital. Constituição Da Republica Portuguesa Anotada. 4. a Ed., vol. I, Coimbra. Coimbra Editora, 2007

DEL MASSO, Fabiano, MIRANDA GONÇALVES, Rubén y ZEFERINO FERREIRA, Rui Miguel. A (Re)Invenção do Estado do Século XXI: O Regresso ao Liberalismo como Suporte do Sistema Democrático. Revista Internacional Consinter de Direito, Vol. I, 2015, pp. 306-324.

Díaz, Elías. Estado de Derecho: exigencias internas, dimensiones sociales, Sistema, № 125, 1997.

; COLOMER, José Luis. Estado, justicia, derechos. Filosofía y pensamiento. Alianza Editorial, 2002.

DURÁN MARTÍNEZ, Augusto. El Derecho administrativo entre legalidad y derechos fundamentales. Revista de Derecho, Facultad de Derecho de la Universidad de Montevideo, №, 12, 2007, pp. 129-134.

FERNÁNDEZ GARCÍA, Eusebio. Hacia un concepto restringido de Estado de Derecho. Los derechos: entre la ética, el poder y el derecho, Dykinson, Madrid, 2000 pp. 103-122.

FREITAS DO AMARAL, Diogo. Curso de Direito Administrativo, Volume I, Almedina, Coimbra, 2016.

GOMES, Carla Amado. A Responsabilidade e as suas circunstâncias. Anotação ao Acórdão do STA, de 4 de dezembro de 2003, in Cadernos de Justiça Administrativa n. ${ }^{-45}$, maio/junho 2004.

GONÇALVES, Fernando; ALVES, Manuel João; VIEIRA, Vítor Manuel Freitas; et al. Novo Código do procedimento Administrativo. Anotado e comentado, Almedina, 2015.

JUSTEN FILHO, Marçal, Curso de Direito Adminsitrativo, $2^{\text {a }}$ Edición, Editorial Saraiba, 2006.

LACERDA, Dimas de. Responsabilidade Civil Extracontratual do Estado e Contencioso Administrativo, Braga, 1986

MACHADO, Jónatas; NOGUEIRA da Costa, Paulo; HILÁRIO, Esteves Carlos. Direito Constitucional Angolano, Coimbra Editora, Coimbra, 2013. 
MACHADO, Jónatas. Liberdade Religiosa Numa Comunidade Constitucional Inclusiva: Dos Direitos Da Verdade Aos Direitos Dos Cidadãos, Coimbra Editora, Coimbra, 1996).

MAGALHÃES, Maria Manuela; ALVES, Dora Resende. Noções de direito constitucional e ciência política. Editora: Rei dos livros. 2000

MIRANDA GONÇALVES, Rubén; CARBAJALES NEIRA, Cristian, "El Derecho de autodeterminación como Derecho Humano del Pueblo saharaui". Derechos Humanos y Juventud, Xunta de Galicia, 2015, pp. 395-432.

MIRANDA, Jorge. Direitos Fundamentais: Introdução Geral, Lisboa, 1999.

OLIVEIRA, Fernanda Paula; FIGUEIREDO DIAS, José Eduardo de Oliveira. Noções Fundamentais de Direito Administrativo, Almedina, Coimbra, 2016.

PECES-BARBA MARTíNEZ, Gregorio. Derecho Positivo de los Derechos Humanos. Editorial Debate, Madrid, 1987.

PEREIRA MENAUT, Antonio-Carlos. Lecciones de Teoría Constitucional, $2^{\mathrm{a}}$ edición, Colex, Madrid.

PÉREZ LUÑO, Antonio E., "Los Derechos Fundamentales". Temas clave de la Constitución Española. Dir. Pedro de Vega, 6ª edición, p. 46.

PORTUGAL. Constituição da Republica Portuguesa, 7. a revisão, 2005, consultada em https://www.parlamento.pt/ArquivoDocumentacao/Documents/CRPVIIrevisao.pdf. Último acesso: 27 de julho de 2017.

Lei n. - 67/2007, de 31 de dezembro, consultada em http://www.pgdlisboa.pt/leis/lei_mostra_articulado.php?nid=2073\&tabela=leis. Último acesso: 27 de julho de 2017

RODRÍGUEZ-ARANA MUÑOZ, Jaime, "El marco constitucional del Derecho Administrativo. (El Derecho Administrativo Constitucional" Anuario da Faculta de de Dereito da Universidade da Coruña, № 15, 2011, pp 85-100.

SOUSA, Marcelo Rebelo de; MATOS, André Salgado. Direito Administrativo Geral. Tomo I, 3. ㄹ. Edição, Dom Quixote, Lisboa, 2004

2. Edição, Dom Quixote, Lisboa, 2009

Direito Administrativo Geral, Tomo III (Atividade Administrativa),

ZAFRA VALVERDE, José. Teoría Fundamental del Estado, Tomo I, Universidad de Navarra, Pamplona, 1990. 